and other similar ones might be responsible for the presence of "antibodies" against human enteroviruses in bovine sera.
N. NATH
S. BALAYA
L. N. Mohapatra

Department of Microbiology,

All India Institute of Medical Sciences,

New Delhi-16

Received May 19, 1970.

1 Hammon, W. McD., Mack, W. N., and Reeves, W. C., $J$. Immunol., 57, 285 (1947).

2 Bartell, P., and Klein, M., Proc. Soc. Exp. Biol. Med., 90, 597 (1955).

${ }^{3}$ Laplaca, M., Portolani, A. M., and Lamieri, C., Arch. Ges. Virusforsch., 17, 98 (1965).

${ }^{4}$ Burki, F., Zbl. Vet. Med., 9, 999 (1962).

5 Moll, T., and Davis, A. D., Amer. J. Vet. Res., 20, 27 (1959).

\section{Human Blastocyst grown in vitro in Ovulation Cervical Mucus}

HUMAN spermatozoa invariably live longer in ovulation cervical mucus than in their own seminal fluid. This can be observed in slide cover glass or capillary tube preparations. At ovulation the cervical mucus is most abundant, possesses the lowest viscosity or spinnbarkeit, is most translucent, contains the highest water concentration and fewest cells, is most alkaline, permits maximum spermatozoan penetration, contains the maximum of glycogen, maltose, mannose, fructose, fucose, hexosamine, glutamic acid, taurine, methionine, lysine, aspartic acid, glycine, alanine, valine, serine, arginine, cholesterol, lipid, phosphorus, and sodium chloride. It possesses thromboplastic activity and is bacteriostatic. Blood group substances corresponding to the blood group of the individual occur in the cervical secretion in high titre if the person is a secretor ${ }^{2}$.

An ovum was aspirated from its follicle in the follicular fluid by means of a sterile $5 \mathrm{ml}$. syringe and an 18 gauge needle passed through the ovarian tissue $2 \mathrm{~mm}$ from the edge of the follicle, then into it posteriorly to prevent leakage. This is the method used for obtaining follicular oocytes and ova for previous studies on in vitro fertilization and cleavage ${ }^{2-8}$. The ovum was taken from a $34 \mathrm{yr}$ old patient undergoing laparotomy for fibromyomata uteri, on the fourteenth day of a regular 28 day menstrual cycle. It was kept in the follicular fluid at body temperature.

After the abdomen was closed, the patient was placed in the modified lithotomy position, the portio of the cervix exposed and cleansed with a cotton swab. With a sterile $5 \mathrm{ml}$. syringe and a bevelled 16 gauge needle $1.2 \mathrm{ml}$. of the watery, clear cervical mucus was aspirated from the mid-cervical canal, after which it was expressed into a sterile Petri dish. The ovum in its follicular fluid was then expressed into the cervical mucus and identified under the dissecting microscope. It was mature in that the first polar body could be made out clearly through the sufficiently translucent corona cells. A ring of 'Vaseline' was placed around the preparation to prevent it from spreading. A drop of semen from the husband with normal spermatozoan count and morphology was added to the preparation, and finally very small pieces of the tubal fimbriae. The Petri dish was covered, placed in a moist chamber in the presence of $20 \%$ oxygen, and kept at body temperature. The primary objective was to simulate the natural environment as much as possible.

After 5 days of incubation the ovum was in the blastocyst stage. The criteria and those used previously concerning fertilization were the same as those cited by Edwards et al. ${ }^{9}$. The blastocyst was then transferred by means of a capillary pipette filled with physiological saline onto a glass slide,

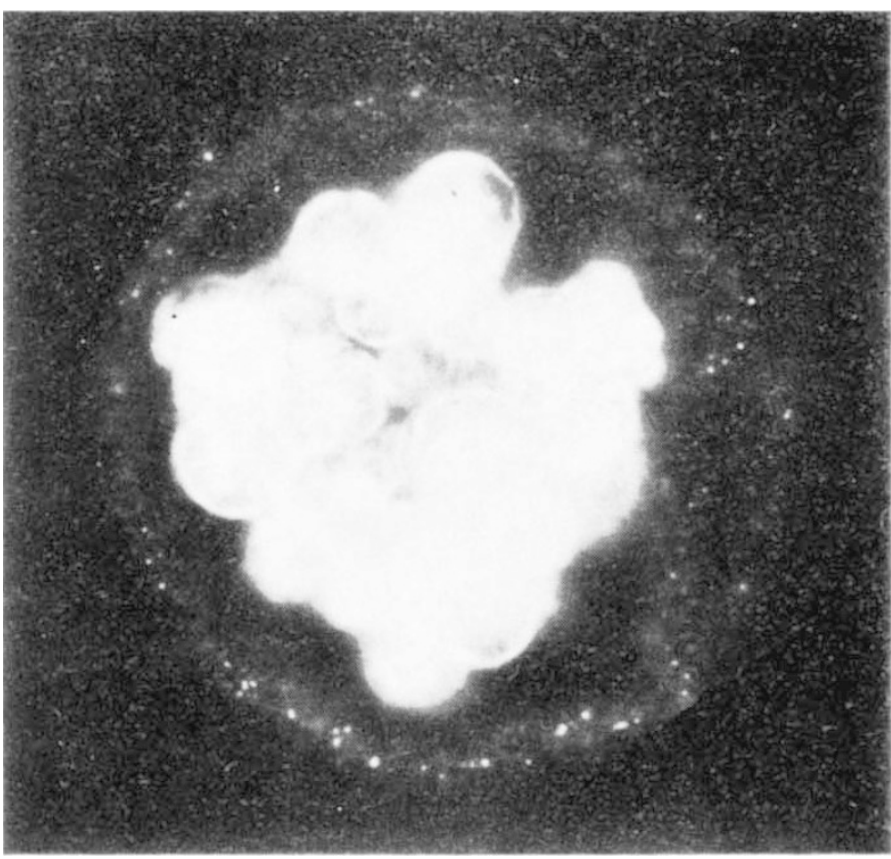

Fig. 1 Human blastocyst grown in ovulation phase cervical mucus 5 days after fertilization. (Phase contrast, $\times 240$.)

covered with a cover glass supported and sealed with a 'Vaseline' ring. It was photographed in phase contrast (Fig. 1).

The grossly normal blastocyst of approximately 100 cells, shown in optical section, was not transferred in utero in that the patient was only 5 days post-multiple myomectomies. Otherwise, there was no discernible contraindication for a successful transfer in vitro and continued development. This is scheduled for patients with ligated or excised fallopian tubes who may want a child, with the ova obtained by culdoscopy or laparoscopy.

\section{LANIRUM B. Shettles}

Department of Obstetrics and Gynecology,

College of Physicians and Surgeons of Columbia University, New York

Received November 13, 1970.

Shettles, L. B., J. Reprod. Med., 3, 43 (1969).

${ }^{2}$ Shettles, L. B., Amer. J. Obstet. Gynec., 66, 235 (1953).

${ }^{3}$ Shettles, L. B., Trans. NY Acad. Sci., 17, 99 (1955).

4 Shettles, L. B., Amer. J. Obstet. Gynec., 76, 398 (1958).

${ }^{5}$ Shettles, L. B., Ovum Humanum (Urban and Schwarzenberg, Munich, 1960).

${ }^{6}$ Shettles, L. B., Obstet. Gynec., 20, 750 (1962).

7 Shettles, L. B., Bull. Sloane Hospital for Women, 10, 246 (1964).

${ }^{8}$ Shettles, L. B., in Scientific Foundations of Obstetric's and Gynecology (edit. by Philipp, E. E., Barnes, J., and Newton, M.) (Heinemann, London, 1970).

${ }^{9}$ Edwards, R. G., Steptoe, P. C., and Purdy, J. M., Nature, 227, 1307 (1970).

\section{Capacitation of Hamster Spermatozoa by $\beta$-Glucuronidase}

CAPACITATION, or the ability for immediate penetration of the ovum, occurs when epididymal sperm of the golden hamster (Mesocricetus auratus) are incubated in the presence of follicular fluid ${ }^{1-3}$. Yanagimachi has reported that sperm motility is maintained by a dialysate of detoxified bovine follicular fluid, but capacitation of the sperm does not occur unless a watersoluble non-dialysable fraction is also provided ${ }^{4}$. The chemical nature of these factors has not yet been determined. Because ovarian follicles, particularly those in atresia, are known to 